Türk Turizm Araştırmalari Dergisi
2019,3(3): 236-244.
ISSN: 2587-0890 Dergi web sayfasi: $\underline{\text { https://www.tutad.org }}$

\title{
SPA Ziyaretçilerini Motive Eden Unsurların Demografik Özelliklere Göre İncelenmesi*
}

Dr. Yunus TOPSAKAL

Adana Bilim ve Teknoloji Üniversitesi, İşletme Fakültesi, Turizm İşletmeciliği, Adana. e-posta: topsakal.yunus@gmail.com

ORCID: https://orcid.org/0000-0003-3202-5539

Dr. Öğr. Üyesi Pınar ÇELİK

Akdeniz Üniversitesi, Sosyal Bilimler Fakültesi, Turizm İşletmeciliği, Antalya. e-posta: pinarcelik@akdeniz.edu.tr ORCID: https://orcid.org/0000-0003-0599-4086

Öz

Günümüzde SPA (salus per aqua) sektörü kentleşme, gürültü, hava kirliliği, stres ve hızlı yaşlanma gibi nedenlerden dolayı büyümeye başlamıştır. Çünkü ziyaretçiler tatil esnasında zihnen ve bedenen rahatlamak, dinlenmek ve tedavi amaciyla konakladıkları tesislerde sunulan SPA hizmetlerinden yararlanmaktadır. Fakat ziyaretçileri SPA hizmeti almak için motive eden unsurlar ve beklentiler yaş gibi demografik özelliklere göre farklılaşabilmektedir. Bundan dolayı, konaklama tesislerinde sunulan SPA hizmetlerinin emtialaşmadan kurtulup farklılaşması gerekmektedir. SPA sektörü büyümesine rağmen, literatürde bu pazarı daha iyi anlamak için çok kısıtlı çalışma yapılmıştır. Bu bağlamda araştırmanın amacı, ziyaretçilerin tatil esnasında otel SPA deneyimlemeye motive eden unsurların yerli ziyaretçi, yabancı ziyaretçi ve yaş gibi demografik özelliklere göre belirlenmesidir. Çalışmada SPA deneyimi için motivasyon ölçeği kullanılmıştır. Veriler Mayıs 2018'de Antalya'da faaliyet gösteren beş yıldızlı otel SPA'sı kullanan ziyaretçilere gönüllülük esasına göre uygulanan anket ile toplanmıştır. Toplam 140 anket çalışmada kullanılmıştır. Sonuçlara göre en yüksek algıya sahip olan ifade 'ruhsal refahlık aramak' ifadesiyken, en az algyya sahip ifade ise 'modaya uygun biri olarak görülmek' ifadesidir. Son olarak bulgular temelinde uygulamaya yönelik önerilerde bulunulmuştur.

Anahtar Kelimeler: SPA, Ziyaretçi Motivasyonu, Otel, Antalya.

Makale Gönderme Tarihi: 23.10.2018

Makale Kabul Tarihi: 02.07.2019

\section{Önerilen Atıf:}

Topsakal, Y. ve Çelik, P. (2019). SPA Ziyaretçilerini Motive Eden Unsurların Demografik Özelliklere Göre İncelenmesi, Türk Turizm Araştırmaları Dergisi, 3(3): 236-244.

(C) 2019 Türk Turizm Araştırmaları Dergisi.

* Bu çalışma 19. Ulusal Turizm Kongresinde sözlü olarak sunulmuş ve bildiri kitabına basılmıştır. 


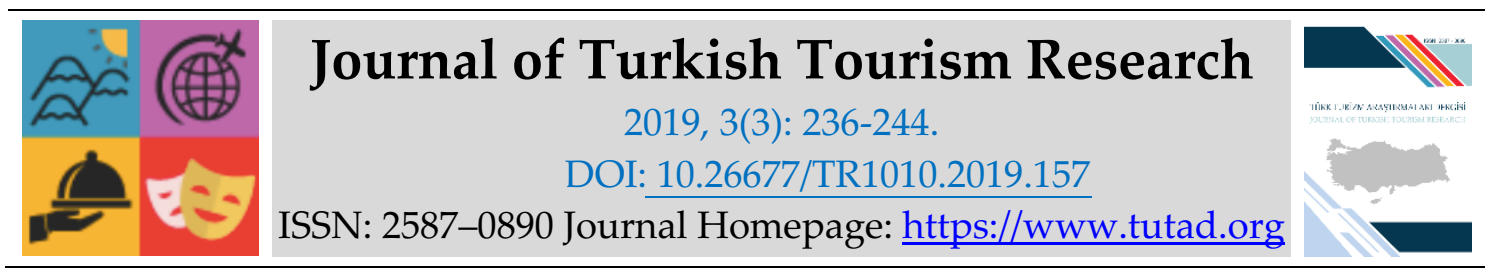

\title{
$\underline{\text { RESEARCH PAPER }}$
}

\section{Investigation the Motivating Factors of the SPA Visitors by Demographic Characteristics}

Dr. Yunus TOPSAKAL

Adana Science and Technology University, Faculty of Management, Tourism Management, Adana. e-mail: topsakal.yunus@gmail.com

ORCID: https://orcid.org/0000-0003-3202-5539

Asst. Prof. Dr. Pınar ÇELIK

Akdeniz University, Faculty of Social Science, Tourism Management, Antalya. e-mail: pinarcelik@akdeniz.edu.tr

ORCID: https://orcid.org/0000-0003-0599-4086

\begin{abstract}
Nowadays, the SPA (salus per aqua) sector has started to grow due to rapid urbanization, noise pollution, air pollution, stress and aging. During the holidays, visitors benefit from SPA services offered in the facilities where they stay to relax and treatment. However, the factors that motivate visitors to buy SPA services and visitors expectations can vary according to demographic characteristics such as age. Therefore, SPA services offered at the accommodation facilities should be differentiated from the similar products. Despite the growth of the SPA sector, limited study has been done in the literature to better understand this market. In this context, the aim of the study is to determine the factors that motivate visitors to experience the hotel SPA during the holidays according to demographic characteristics such as local visitors, foreign visitors and ages. Motivational scale was used to measure SPA experience. The data were collected by a survey that conducted on a voluntary basis in May 2018 in Antalya. A total of 140 questionnaires were used in the study. According to the results, the expression with the highest perception is 'seeking spiritual prosperity', while the least perception is 'to be seen as fashionable place' Finally, practical suggestions were made on the basis of the findings.
\end{abstract}

Keywords: SPA, Visitor Motivation, Hotel, Antalya

Received: 23.10 .2018

Accepted: 02.07.2019

\section{Suggested Citation:}

Topsakal, Y. and Çelik, P. (2019). Investigation the Motivating Factors of the SPA Visitors by Demographic Characteristics, Journal of Turkish Tourism Research, 3(3): 236-244.

(C) 2019 Türk Turizm Araştırmaları Dergisi. 


\section{Gíriş}

Günümüzde yaşanan artan kirlilik, iş stresi, trafik gürültüsü ve kentleşme gibi nedenlerden dolayı, insanlar zihnen ve bedenen çeşitli hastalıklar ile karşı karşıyadır. Günlük rutinden uzaklaşmak için tatil ihtiyacı duyan insanlar, tatil esnasında hastalıkları önlemek, zihnen ve bedenen rahatlamak için SPA (salus per aqua) hizmetlerini kullanmaya başlamıştır. Bundan dolayı, konaklama tesisleri kendi bünyelerinde ziyaretçilere SPA hizmetleri sunmaktadır.

Tabacchi (2010) ziyaretçiler için otel SPA, gündüz SPA, tıbbi SPA ve mineral SPA gibi farklı amaçlar için farklı SPA türleri olduğundan dolayı, SPA'nın genel kabul gören bir tanımının yapılmasının zor olduğunu ileri sürmüştür. SPA kelimesi, Latince 'su aracılığıyla sağlık' anlamına gelen 'salus per aqua' ifadesinin kısaltmasıdır (Frost, 2004). Uluslararası SPA Derneği (ISPA) ise SPA'ları zihin, beden ve ruhun yenilenmesine yardımcı olan, çeşitli profesyonel hizmetlerle genel sağlığı arttırmak amacıyla hizmet veren kurumlar olarak tanımlamıştır (ISPA, 2006). ISPA sunulan imkanlar ve tedavilere göre SPA türlerini sekiz ana kategoride sınıflandırılmıştır: kulüp SPA, kruvaziyer SPA, gündüz SPA, destinasyon SPA, otel SPA, tıbbi SPA, maden suyu kaynağ ${ }_{1}$ SPA ve resort SPA.

SPA yaşam tarzı gittikçe daha popüler hale gelmekte ve tatil esnasında bir SPA deneyimi artık lüks olarak değil, sağlıklı bir yaşam tarzının gerekli bir parçası olarak görülmektedir (Guillet ve Küçükusta, 2016). Sağlıklı ve daha iyi bir yaşam tarzı insanların önemli önceliklerinden biri haline geldiğinden dolayı SPA sektörü büyümeye başlamış ve otellerin veya tatil tesislerinin lüks değil de vazgeçilmez bir unsuru olmuştur (Mandelbaum ve Lerner, 2008). Ziyaretçilerin artan SPA terapileri talebi doğrultusunda SPA tanıtım ve pazarlaması SPA işletmecileri, otelciler, tatil köyleri ve turistik yerlerin tanıtım ve pazarlamasında önemli bir role sahip olmuştur. Bundan dolayı literatürde SPA ile ilgili çalışmalar hız kazanmıştır. SPA ile ilgili çalışmaların büyük bir çoğunluğu ziyaretçi hizmetlerine yönelik beklenti ve tercihlere (McNeil ve Ragins, 2004; Sherman vd., 2007) ve ziyaretçi motivasyonlarına (Lo vd., 2013; Koh vd., 2010; Tsai vd., 2011) odaklanmıştır. Çalışmalar, SPA deneyimini etkileyen kritik faktörleri veya nitelikleri tanımlasa da, çoğu çalışma çeşitli SPA deneyiminin ziyaretçiler için ne anlam ifade ettiğini ve demografik özelliklere göre SPA algısının nasıl farklılaştığını göz ardı etmiştir. Bundan dolayı araştırmanın amacı, ziyaretçileri tatil esnasında SPA deneyimlemeye motive eden unsurların yerli ziyaretçi, yabancı ziyaretçi, yaş gibi demografik özelliklere göre belirlenmesidir. Bu kapsamda SPA ziyaretçilerinden anket ile veri toplanmıştır. Toplanan veriler analiz edilerek önerilerde bulunulmuştur.

\section{LITERATÜR TARAMASI}

Monteson ve Singer (2004) SPA kullanan ziyaretçilerin pazar paylarını artırmak ve rekabet avantajı elde etmek isteyen tesis temelli SPA'ların sahipleri ve işletmecileri için bilgi sağlamak amacıyla araştırma gerçekleştirmiştir. ABD'deki SPA ziyaretçilerinin demografik özelliklerini, hangi SPA hizmetlerini kullandıklarını, neden SPA tesislerine gittiklerini ve SPA deneyiminden sonra nasıl hissettiklerini incelemiştir. Mak vd., (2009) Hong Kong'daki SPA ziyaretçilerinin motivasyon faktörlerini incelemiştir. Sonuç olarak gevşeme ve rahatlama, sağlık ve güzellik, kaçş̧ ve kendini ödüllendirme olarak 21 motivasyon grubu belirlemiştir.

Koh vd., (2010) ABD'deki SPA ziyaretçileri tarafından beklenen faydaları değerlendirmiş ve SPA kullanımının sosyalleşme, rahatlama, sağlık ve yenilenme gibi faydaları olduğu sonucuna varmıştır. Tsai vd., (2011) bir otel SPA hizmeti için en çok belirtilen nedenin rahatlama olduğunu ve en sık alınan hizmetin ise vücut masajı olduğunu yapmış olduğu çalışmasında sonuç olarak bulmuştur. 
Lo vd., (2013) yöneticilerin ve ziyaretçilerin turizm SPA deneyimleri ve SPA deneyimini zenginleştiren faktörler hakkındaki algılarında farklılaştıklarını ileri sürmüştür. Hem sektör yöneticileri hem de ziyaretçileri, ziyaretçilerin SPA deneyimini etkileyen kritik faktörler olarak yerelleştirilmiş temayı, ürünler ve tedavileri, kişiselleştirilmiş hizmetleri ve mesleki beceriler ve tutumları belirlemişlerdir. Ziyaretçiler ayrıca SPA tesislerinin mahremiyetini, hizmet mesafesini ve temizliğini de kritik başarı faktörü olarak görmüştür. Yöneticiler ise ziyaretleri öncesinde müşterileri ziyaretçiler ile etkileşim, iletişimin ve SPA çeşitliliğinin önemli faktörler olduğunu eklemiştir. Küçükusta vd., (2013) ziyaretçilerin Hong Kong'daki otel SPA'larını neden tercih ettiğini ortaya çıarmak amacıyla bir çalışma gerçekleştirmiştir. Sonuç olarak otel SPA'larının tercih edilmesinin altındaki nedenlerin profesyonel becerileri, ürün ve hizmet bilgileri, gizliliği, tesis çeşitliliği ve ürün markası olduğunu bulmuştur.

Lo vd., (2015) SPA hizmet kalitesinin boyutlarını ve niteliklerini tanımlayarak, bu boyutların ziyaretçilerin otelden veya tatil köyünden memnun kalmaları üzerindeki etkisini araştırmıştır. Sonuçlara göre duyarlılık, memnuniyeti açıklamanın en önemli belirleyici faktörü olarak bulunmuş, bunu güvenilirlik ve empati takip etmiştir. Erdem vd., (2015) konaklama işletmelerinde SPA hizmetlerindeki insan kaynaklarına odaklanmış ve departmanlardaki insan kaynaklarının profilinin ortaya çıarılmasını amaçlayarak çalışma gerçekleştirmiştir. Araştırmanın verileri, Antalya'da faaliyet gösteren beş yıldızlı konaklama işletmelerinin SPA birimlerindeki personelden anket yolu ile elde edilmiştir. Bulgulara göre insan kaynaklarının ağırlıklı olarak lisans ve lise mezunu olduğu, yaklaşık üçte birinin herhangi bir seviyede örgün turizm eğitimi almadığ

Yalçın (2018) ise terapi için deniz suyunu kullanan konaklama tesislerinin yöneticileri ile yarı yapılandırılmış görüşmeler yapmıştır. Araştırma sonucunda, deniz suyu potansiyelinden yeterince faydalanılmadığı ve deniz suyu uygulamalarını tercih eden ziyaretçilerin sağlık farkındalığı ve gelir seviyesi yüksek olan ziyaretçiler olduğu ortaya çıkmıştır.

Demografik değişkenlerin turist motivasyonlarına olan etkisi de turizm çalışmalarında yer almıştır (Gitelson ve Kerstetter, 1990). Uysal vd., (1990) medeni durum ve yaş değişkenlerini tatil amaçlı seyahat edenlere yönelik seyahat motivasyon çalışmasına dahil etmiştir. Milliyetlere ve sağlık sistemlerine göre de SPA kullanımı değişiklik gösterebilmektedir. Avrupalı SPA kullanıcıları genellikle SPA deneyimini iyileştirici veya tedavi amaçlı olduğu algısını benimsemektedir (Douglas, 2001). Bu algının, sosyal sigorta sisteminin bir parçası olarak Avrupalıların SPA'ları ziyaret etme uygulamasıyla ilişkili olabildiği iddia edilmiştir (Frost, 2004).

Yukarıdaki literatür çerçevesinde SPA ile ilgili çeşitli destinasyonu örneklem alan çalışmalar literatürde mevcuttur. Bu çalışmaların incelendiğinde genel olarak çalışmalar SPA kullanımına iten motivasyonları belirlemeye yönelip gerçekleştirilmiştir. Demografik değişkenlerin turist motivasyonuna olan etkisi ile ilgili çalışmalar mevcut iken, SPA kullanıcıların demografik değişkenler ve özellikle yerli-yabancı turist kapsamında farklılaşıp farklılaşmadığını belirlemek üzere kısıtlı çalışma mevcuttur.

\section{YÖNTEM}

Araştırma amaçlarına ulaşmak için anket yöntemi ile veri toplanmıştır. Anket üç bölümden oluşmaktadır. İlk bölümde katılımcıların demografik bilgileri ile ilgili veriler toplamak amacıyla uyruk, yaş, cinsiyet, medeni durum, eğitim durumu, kaç kez SPA deneyimi olduğu ve seyahate eşlik eden soruları yöneltilmiştir. Anketin ikinci bölümünde SPA'nın nasıl bir yer olarak algılandığı sorusu yöneltilmiştir. Bu bölümde Mak vd., (2009) tarafından geliştirilen toplam sekiz ifadeli ölçek kullanılmıştır. Bu ölçek "Evet" ve "Hayır" olarak yöneltilmiştir. Anketin üçüncü 
bölümünde ise Mak vd., (2009) tarafından geliştirilen SPA deneyimi için motivasyon ölçeği kullanılmıştır. SPA motivasyon ölçeğinde toplam 19 ifade 5'li Likert ölçeğiyle katılımcılara yöneltilmiştir. SPA deneyimi için motivasyon ölçeği toplam dört boyuttan oluşmaktadır. Bu boyutlar arkadaşlık ve akrabalık, sağlık ve bakım, kendini ödüllendirme ve düşkünlük, rahatlama ve kaçış boyutlarıdır. Veriler Mayıs 2018 'de Antalya'da faaliyet gösteren beş yıldızlı otel SPA'sı kullanan ziyaretçilere gönüllülük esasına göre uygulanan anket ile toplanmıştır. Toplam 140 anket çalışmada kullanılmıştır. Toplanan veriler frekans analizi, ortalama analizi, faktör analizi, t-test ve ANOVA analizlerine tabi tutulmuştur ve yorumlanmıştır.

\section{BULGULAR VE TARTIŞMA}

Katılımcların uyruk, cinsiyet, yaş, medeni durum, eğitim durumu, eşlik eden ve SPA deneyimi frekans analizine tabi tutulmuş ve sonuçlar Tablo 1'de sunulmuştur. Tablo 1 incelendiğinde katılımcıların \%55,7'sinin yerli, \%44,3'ünün yabancı olduğu belirlenmiştir. Cinsiyet olarak \%39,3 erkek ve \%60,7 kadın katılımcıdan oluşmaktadır. Katılımcıların büyük bir çoğunluğu "26-34" yaş aralığı grubunda, en az katılımcının ise " 44 ve üzeri" yaş aralığ1 grubunda yer almaktadır. Medeni durum bağlamında katılımcıların \%63,6'sının evli ve \%36,4'ünün bekar olduğu sonucuna ulaşılmıştır. Katılımcıların büyük bir çoğunluğu "önlisans/lisans" eğitim durumu grubunda, en az katılımcı ise "ilkokul" eğitim durumu grubunda yer almaktadır. Eşlik eden olarak \%36,4 yalnız, \%21,4, eş \%20 aile ve \%22,1 arkadaşladır. SPA deneyimi kapsamında ise katılımcıların $\% 49,3$ 'ü “4 ve altı" grubunda, \%16,4'ü “5-8" grubunda ve $\% 34,3$ 'ü “9 ve üzeri” grubunda yer almaktadır.

Tablo 1. Katılımcıların Demografik Özellikleri $(\mathrm{n}=140)$

\begin{tabular}{|c|c|c|c|c|c|}
\hline & f & $\%$ & & f & $\%$ \\
\hline \multicolumn{3}{|l|}{ Uyruk } & \multicolumn{3}{|l|}{ Eşlik Eden } \\
\hline Yerli & 78 & 55,7 & Yalnız & 51 & 36,4 \\
\hline \multirow[t]{2}{*}{ Yabanc1 } & 62 & 44,3 & Eş & 30 & 21,4 \\
\hline & & & Aile & 28 & 20,0 \\
\hline \multicolumn{3}{|l|}{ Cinsiyet } & \multirow[t]{2}{*}{ Arkadaş } & \multirow[t]{2}{*}{31} & \multirow[t]{2}{*}{22,1} \\
\hline \multirow{3}{*}{$\begin{array}{l}\text { Erkek } \\
\text { Kadın }\end{array}$} & \multirow{3}{*}{$\begin{array}{l}55 \\
85\end{array}$} & \multirow{3}{*}{$\begin{array}{l}39,3 \\
60,7\end{array}$} & & & \\
\hline & & & \multicolumn{3}{|l|}{ Yaş } \\
\hline & & & \multirow{4}{*}{$\begin{array}{l}25 \text { ve altı } \\
26-34 \\
35-43 \\
44 \text { ve üzeri }\end{array}$} & 38 & 27,1 \\
\hline \multicolumn{3}{|c|}{ Medeni Durum } & & 39 & 27,9 \\
\hline Evli & 89 & 63,6 & & 35 & 25,0 \\
\hline Bekar & 51 & 36,4 & & 28 & 20,0 \\
\hline \multicolumn{3}{|c|}{ SPA Deneyimi } & \multicolumn{3}{|c|}{ Eğitim Durumu } \\
\hline 4 ve altı & 69 & 49,3 & İlkokul & 15 & 10,7 \\
\hline $5-8$ & 23 & 16,4 & Lise & 35 & 25,0 \\
\hline \multirow[t]{2}{*}{9 ve üzeri } & 48 & 34,3 & Önlisans/Lisans & 74 & 52,9 \\
\hline & & & Lisansüstü & 16 & 11,4 \\
\hline
\end{tabular}

Katılımcılara yöneltilen "SPA'yı nasıl bir yer olarak algılarsınız?" sorusunun frekans analizi sonuçları Tablo 2'de verilmiştir.

Tablo 2'de görüldüğü üzere katılımcıların büyük bir çoğunluğu SPA'yı 'rahatlatıcı yer' olarak görmektedir. İkinci sırada ise SPA 'kendine zevk yaşatılan yer' ve üçüncü olarak 'güzelleştirici bakım yeri’ olarak algılamaktadır. En düşük katılımın olduğu cevap ise "gitmek için modaya 
uygun bir yer" cevabıdır. Mandelbaum ve Lerner'ın (2008) ifade ettiği gibi sağlıklı ve daha iyi bir yaşam tarzı insanların önemli önceliklerinden biri haline geldiğinden dolayı SPA sektörü otellerin lüks değil de vazgeçilmez bir unsuru olmuştur.

Tablo 2. Katılımcıların SPA'yı Nasıl Bir Yer Olarak Algıladıkları

\begin{tabular}{lcccc}
\hline & Evet & $\mathbf{\%}$ & Hayır & $\mathbf{\%}$ \\
\hline Rahatlatıcı yer & 136 & 97,1 & 4 & 2,9 \\
Kendine zevk yaşatılan bir yer & 118 & 84,3 & 22 & 15,7 \\
Güzelleştirici bakım yeri & 103 & 73,6 & 37 & 16,4 \\
Genel sağlığın iyileştirildiği yer & 97 & 69,3 & 43 & 30,7 \\
Belirli bir tıbbi rahatsızlığın iyileştirildiği yer & 67 & 47,9 & 73 & 52,1 \\
Zayıflama tedavilerinin yapıldı̆̆ı yer & 75 & 53,6 & 65 & 46,4 \\
Gitmek için modaya uygun bir yer & 65 & 46,4 & 75 & 53,6 \\
Gitmek için prestijli bir yer & 76 & 54,3 & 64 & 45,7 \\
\hline
\end{tabular}

Tablo 3. Katılımcıların İfadelere Olan Algıları

\begin{tabular}{lcc}
\hline Boyutlar & Ortalama & SS \\
\hline \multicolumn{1}{c}{ Arkadaşlık ve Akrabalık } & \\
\hline Aile bağlarını geliştirmek & 3,22 & 1,30 \\
Aile ile vakit geçirmek & 3,30 & 1,28 \\
Arkadaşlarla vakit geçirmek & 3,29 & 1,27 \\
Arkadaşlık bağlarını arttırmak & 3,27 & 1,29 \\
SPA deneyimini arkadaşları ve aile paylaşmak & 3,20 & 1,29 \\
\hline \multicolumn{2}{c}{ Sağlık ve Bakım } \\
\hline Kilo vermek & 3,27 & 1,23 \\
Görünümümü gençleştirmek & 3,39 & 1,19 \\
Fiziksel çekiciliğimi arttırmak & 3,33 & 1,24 \\
Genel sağlığımı iyileştirmek & 3,20 & 1,33 \\
\hline \multicolumn{1}{c}{ Kendini Ödüllendirme ve Düşkünlük } & \\
\hline Lüks deneyimle kendimi şımartmak & 3,18 & 1,39 \\
Modaya uygun biri olarak görünmek & 2,99 & 1,30 \\
Kendime zevk yaşatmak & 3,26 & 1,34 \\
Çok çalıştığım için kendimi ödüllendirmek & 3,32 & 1,38 \\
\hline \multicolumn{2}{c}{ Rahatlama ve Kaçış } \\
\hline Fiziksel rahatlama aramak & 3,40 \\
Zihinsel huzur aramak & 3,44 & 1,40 \\
Ruhsal ferahlık aramak & 3,52 & 1,29 \\
Tibbi bir durum için tedbir aramak & 3,26 & 1,24 \\
Günlük rutinden uzaklaşmak & 3,45 & 1,28 \\
İş ve sosyal hayatın baskılarından uzaklaşmak & 3,41 & 1,31 \\
\hline
\end{tabular}

Daha sonra gerçekleştirilecek olan t-test ve ANOVA analizleri için motive eden unsurlar ölçeği faktör analizine tabi tutulmuştur. Sonuçlara göre motive eden unsurlar dört boyut altında toplanmıştır. Toplam varyans açıklama oranı $\% 71,440$ 'dır. 'Arkadaşlık ve akrabalık' boyutu toplam beş ifadeden oluşmakta ve Croanbach Alpha (CA) değeri 0,88'dir. 'Sağlık ve bakım' boyutu toplam dört ifadeden oluşmakta ve CA değeri 0,85 'dir. 'Kendini ödüllendirme ve düş̧ünlük' boyutu toplam dört ifadeden oluşmakta ve CA değeri 0,84'dür. 'Rahatlama ve kaçış' boyutu toplam altı ifadeden oluşmakta ve CA değeri 0,90'dır. 
İfadelerin ortalamaları ise Tablo 3'de verilmiştir. İfadelere olan algılara genel olarak bakıldığında en yüksek algıya sahip olan ifade 3,52 ortalama ile "ruhsal refahlık aramak" ifadesiyken, en az algiya sahip ifade 2,99 ile "modaya uygun biri olarak görülmek" ifadesidir. Guillet ve Küçükusta'nın (2016) tatil esnasında bir SPA deneyimi artık lüks olarak değil, sağlıklı bir yaşam tarzının gerekli bir parçası olarak görülmektedir ifadesi bu bulguyu desteklemektedir.

Her bir boyut bağlamında ise ortalama sonuçları şu şekildedir;

- Arkadaşlık ve akrabalık boyutu için en yüksek algıya sahip olan ifade 3,30 ortalama ile "aile ile vakit geçirmek" ifadesiyken, en az algiya sahip ifade 3,20 ile "SPA deneyimini arkadaşları ve aile paylaşmak" ifadesidir.

- Sağlık ve bakım boyutu bağlamında en yüksek algıya sahip olan ifade 3,39 ortalama ile "görünümümü gençleştirmek" ifadesiyken, en az algıya sahip ifade 3,20 ile "genel sağ lı̆̆ımı iyileştirmek" ifadesidir.

- Kendini ödüllendirme ve düşkünlük boyutu için en yüksek algıya sahip olan ifade 3,32 ortalama ile "çok çalıştı̆̆ım için kendimi ödüllendirmek" ifadesiyken, en az algıya sahip ifade 2,99 ile "modaya uygun biri olarak görülmek" ifadesidir.

- Rahatlama ve kaçış boyutu kapsamında en yüksek algıya sahip olan ifade 3,52 ortalama ile "ruhsal refahlık aramak" ifadesiyken, en az algıya sahip ifade 3,26 ile "tıbbi bir durum için tedbir aramak" ifadesidir.

Çalışmanın amaçlarını test etmek için cinsiyet, uyruk, medeni durum, yaş ve eşlik eden kapsamında t-test ve ANOVA analizleri gerçekleştirilmiş ve sonuçlar Tablo 4'de özetlenmiştir.

Tablo 4. t-test ve ANOVA Analiz Sonuçları

\begin{tabular}{llllll}
\hline & & &
\end{tabular}

Cinsiyet, uyruk ve medeni durum ile boyutlar arasında fark olup olmadığını belirlemek amacıyla t-test analizinden faydalanılmıştır (Tablo 4). Cinsiyet ve uyruğa göre boyutlarda fark bulunamamıştır. Medeni duruma göre 'kendini ödüllendirme ve düşkünlük' boyutunda anlamlı farklılık olduğu belirlenmiştir. Evli katılımcıların ‘kendini ödüllendirme ve düşkünlük' boyutuna olan algısının bekar katılımcılara kıyasla düşük olduğu belirlenmiştir. Bundan dolayı SPA kullanan bekar katılımcıların evlilere göre daha çok kendini ödüllendirme ve düşkünlük için SPA tercih ettiği söylenebilir.

Yaş ve eşlik eden bağlamında boyutlar arasında fark olup olmadığını belirlemek için ANOVA analizinden faydalanılmıştır. Katılımcıların yaş gruplarına göre farklılık belirlenmemişken, eşlik edene göre 'arkadaşlık ve akrabalık' boyutunda anlamlı bir farklılık belirlenmiştir. Bu farklılık ise 'yalnız' SPA kullanan katılımcılar ile 'aile ve arkadaş' ile SPA kullananlar arasında 
bulunmaktadır. Yalnız SPA kullanan katılımcıların 'arkadaşlık ve akrabalık' boyutuna olan algısı ‘aile ve arkadaş' ile SPA kullanan katılımcıların algısından düşüktür.

\section{SONUÇ VE ÖNERILER}

Ziyaretçilerin tatil esnasında otel SPA deneyimlemeye motive eden unsurların uyruk, yaş, cinsiyet gibi demografik özelliklere göre belirlenmesi amacıyla anket yöntemi ile veri toplanmış ve analizlere tabi tutulmuştur. Genel olarak 'rahatlama ve kaçış' boyutunun diğer boyutlara kıyasla daha yüksek algıya sahip olması ve katılımcıların SPA'yı rahatlayıcı yer, kendine zevk yaşatılan ve genel sağlığın iyileştirildiği yer olarak görmeleri literatürdeki bazı çalışmalar (Koh vd., 2010; Tsai vd., 2011) tarafından desteklenmektedir. Sonuçlara göre sadece medeni durum ve eşlik eden bağlamında farklılık olduğu belirlenmiştir. Evli katılımcıların 'kendini ödüllendirme ve düşkünlük' boyutuna olan algısının bekar katılımcılara kıyasla düşüktür ve 'yalnız' SPA kullanan katılımcıların 'arkadaşlık ve akrabalık' boyutuna olan algısı 'aile ve arkadaş' ile SPA kullanan katılımcıların algısından düşüktür. Çalışma sonuçları kapsamında şu önerilerde bulunulmuştur;

- Katılımcıların otel SPA'sını rahatlayıcı, kendine zevk yaşatılan ve güzelleştirici bakım yeri olarak görmelerinden dolayı otel SPA'ları tanıtım ve pazarlamada bu özellikleri ön plana çıkararak potansiyel ziyaretçileri çekerek rekabet avantajlarını arttırabilirler,

- Otel SPA'ları ziyaretçilerin aile ile vakit geçirmeleri amacıyla SPA'ları bu kapsamda tasarlayabilir,

- Otel SPA'ları daha çok görünümü güzelleştirme amacıyla tercih edildiğinden dolayı görünümü güzelleştirme SPA paketleri oluşturularak ve bu pakette indirim uygulayarak potansiyel ziyaretçiler çekilebilir,

- Ziyaretçilerin ruhsal refahlık ile ilgili tatmin olmalarını arttırmaya yönelik uygulamalar geliştirilebilir.

Çalışma sadece Antalya destinasyonunda otel SPA kullananlardan toplanan veriler ile gerçekleştirilmiştir. Farklı destinasyonlardaki otel SPA'ları ve diğer SPA türlerini tercih edenler ile ilgili çalışma yapılarak kıyaslama yapılması konunun daha detaylı bir şekilde ele alınıp incelenmesine olanak sağlayabilir.

\section{KAYNAKÇA}

Douglas, N. (2001). Travelling for Health: Spa and Health Resorts. (Editor) Douglas, N. and Derrett, R.: Special Interest Tourism: Context and Cases, içinde (ss. 261-268) Australia: John Wiley \& Sons.

Erdem, B., Gülcan, B. ve Chykynov, S. (2015). Konaklama İşletmelerinde SPA \& Wellness Hizmetlerinde Çalışan İşgörenlerin Profili: Antalya'daki Beş Yıldızlı Otel İşletmelerinde Bir Araştırma, Akademik Bakış Uluslararası Hakemli Sosyal Bilimler Dergisi, (48): 238-257.

Frost, G. J. (2004). The SPA as a Model of an Optimal Healing Environment, The Journal of Alternative and Complementary Medicine, 10(1): 85-92.

Gitelson, J. and Kerstetter L. (1990). The Relationship between Sociodemographic Variables, Benefits Sought and Subsequent Vacation Behavior: A Case Study, Journal of Travel Research, 28(3): 24-29.

Guillet, B. D. and Küçükusta, D. (2016). SPA Market Segmentation According to Customer Preference, International Journal of Contemporary Hospitality Management, 28(2): 418-434. 
ISPA. (2006). ISPA 2004 Consumer Trends Report - Executive Summary. [Online] https://experienceiSPA.com/iSPAmedia/news/item/the-iSPA-2004-consumer-trends-reportexecutive-summary [Erişim Tarihi: 15.08.2018].

Koh, S., Yoo, J. and Boger, C. (2010). Importance-Performance Analysis with Benefit Segmentation of SPA Goers, International Journal of Contemporary Hospitality Management, 22(5): 718-735.

Küçükusta, D., Pang, L. and Chui, S. (2013). Inbound Travelers' Selection Criteria for Hotel SPAs in Hong Kong, Journal of Travel and Tourism Marketing, 30(6): 557-576.

Lo, A., Corrine, W. and Tsai, H. (2015). The Impact of Service Quality on Positive Consumption Emotions in Resort and Hotel SPA Experiences, Journal of Hospitality Marketing \& Management, 24(2): 155-179.

Lo, A., Qu, H. and Wetprasit, P. (2013). Realms of Tourism SPA Experience: The Case of Mainland Chinese Tourist, Journal of China Tourism Research, 9(4): 429-451.

Mak, A., Wong, K. and Chang, R. (2009). Health or Self-Indulgence? The Motivations and Characteristics of SPA-Goers, The International Journal of Tourism Research, 11(2): 185-199.

Mandelbaum, R. and Lerner, G. (2008). PKF Industry Analysis: Hotel Operators Massage More Profits from Their SPA Operations, Cornell Hospitality Quarterly, 49(2): 99-104.

McNeil, K. R. and Ragins, E. J. (2004). Staying in the SPA Marketing Game: Trends, Challenges, Strategies and Techniques, Journal of Vacation Marketing, 11(1): 31-39.

Monteson, P. A. and Singer, J. (2004). Marketing a Resort-Based SPA, Journal of Vacation Marketing, 10(3): 282-287.

Sherman, L., Clemenz, C. and Philipp, S. (2007). Gender-Based Service Preferences of SPA-Goers, (Editor) Chen, J. S.: Advances in Hospitality and Leisure içinde (ss. 217-299) UK: Emerald Group Publishing Limited.

Tabacchi, M. H. (2010). Current Research and Events in the SPA Industry, Cornell Hospitality Quarterly, 51(1): 102-117.

Tsai, H., Yeung, S. and Yim, P.H.L. (2011). Hotel Selection Criteria Used by Mainland Chinese and Foreign Individual Travelers to Hong Kong, International Journal of Hospitality and Tourism Administration, 12(3): 252-267.

Uysal, M., Zimmerer, P. and Bonn, M. (1990). Marketing Resorts to the 'Gray' Traveler, Leisure Information Quarterly, 16(4): 4-7.

Yalçın, B. (2018). Deniz Suyunun SPA-Wellness Turizmi Kapsamında Kullanımı, 4. Ulusal Deniz Turizmi Sempozyumu, 23-24 Şubat 2018. İzmir, ss: 1-10. 